\title{
Depressed serum high density lipoprotein cholesterol levels in veterans with spinal cord injury
}

\author{
W A Bauman MD, A M Spungen MS, You-Gong Zhong MD, J L Rothstein BS, \\ C Petry BS, S K Gordon MD
}

Spinal Cord Damage Research Center and SCI Service, Veterans Affairs Medical Center, 130 West Kingsbridge Road, Bronx, New York 10468, and Departments of Medicine and Rehabilitation Medicine, Mount Sinai Medical Center, New York 10029, USA.

Cardiovascular diseases are the most frequent cause of death among persons with spinal cord injury (SCI), and these diseases are reported to occur prematurely in the disabled compared to the able bodied population. The mechanism of accelerated coronary heart disease (CHD) in persons with SCI may be partially explicable on the basis of the lipoprotein profile. We performed fasting lipoprotein determinations on 100 veterans with SCI, 50 with paraplegia and 50 with quadriplegia, and 50 veteran controls. The mean age of the subjects with SCI was $47.8 \pm 1.4$ years with a duration of injury of $16.3 \pm 1.2$ years. The mean serum high-density lipoprotein (HDL) cholesterol was depressed in subjects with paraplegia or quadriplegia compared to controls $(37 \pm 1$ or $40 \pm 1$ versus $48 \pm 2 \mathrm{mg} / \mathrm{dL}, p<0.0001)$. Although serum total cholesterol was lower $(p<0.01)$ in subjects with SCI than in controls, there was no significant difference in mean serum low-density lipoprotein (LDL) cholesterol. Thirtyseven percent of subjects with SCI have serum HDL cholesterol levels less than $35 \mathrm{mg} / \mathrm{dL}$ with no significant difference in lipoprotein distribution between high and low cord lesions. Eighteen percent of individuals with SCI have an absolute elevation of LDL cholesterol (greater than $160 \mathrm{mg} / \mathrm{dL}$ ). About $40 \%$ of those with SCI and LDL cholesterol levels between 130 and $160 \mathrm{mg} / \mathrm{dL}$ also have serum HDL cholesterol values below $35 \mathrm{mg} / \mathrm{dL}$, all of whom would have their serum HDL cholesterol level undetected if lipoprotein profiles were performed according to present recommendations - that is, only if the serum total cholesterol is elevated. The ratio of serum total cholesterol to HDL cholesterol and serum LDH cholesterol to HDL cholesterol, commonly used ratios for risk of CHD, were calculated and are elevated in groups with SCI. In a subgroup of 12 subjects with paraplegia, a linear correlation is noted between serum HDL cholesterol values and cardiopulmonary fitness by determination of $\mathrm{VO}_{2}$ max by upper body ergometry. Also, a linear correlation $(p=0.02)$ is found between serum HDL cholesterol and insulin sensitivity as determined by the minimalmodel method.

Keywords: paraplegia; quadriplegia; lipoprotein cholesterol; cardiopulmonary fitness; insulin sensitivity; diabetes mellitus.

Diseases which occur with age are being reported in persons with spinal cord injury (SCI) ${ }^{1-5}$ In one study ${ }^{2}$ cardiovascular diseases were the most frequent cause of death among persons with SCI more than 30 years post injury (46\% of all deaths) and among those more than 60 years of age $(35 \%$ of deaths). Cardiovascular disease mortality has been reported to occur at younger ages in persons with SCI than in the nondisabled population. ${ }^{2}$ The lipid profile determines a portion of the risk of cardiovascular disease. ${ }^{6-10}$ An increased level of activity is associated with reduced risk of $\mathrm{CHD},{ }^{11}$ which may be largely due to the direct relationship between activity and high density lipoprotein (HDL) cholesterol. The general recommendation to perform a com- 
plete lipoprotein profile in individuals only if the total serum cholesterol is greater than $240 \mathrm{mg} / \mathrm{dL}$ may not be appropriate for those who are disabled, since the serum HDL cholesterol has been reported to be markedly reduced in persons with SCI. ${ }^{12-14}$ Thus, we performed a complete lipoprotein profile in 100 subjects with SCI, equally divided between those with paraplegia or quadriplegia, and compared the results to those obtained in 50 able bodied veteran controls. Since both carbohydrate metabolism $^{15-19}$ and level of activity ${ }^{12,20,21}$ have each individually been shown to influence the serum HDL cholesterol level, in a subset of 12 subjects with paraplegia cardiovascular fitness and peripheral insulin sensitivity were determined and compared to the level of serum HDL cholesterol.

\section{Methods}

Fasting lipoprotein determinations were performed on 50 veterans with paraplegia, 50 with quadriplegia, and 50 veteran controls. The groups were matched for age and body mass index (BMI). Informed consent was obtained from all subjects. The serum total cholesterol and triglycerides were assayed on SMAC (Technion Instruments) using the enzymatic method. The serum HDL cholesterol was determined by the dextran sulfate method (Technicon HDL cholesterol precipitating reagent, Technicon Instruments Corp, Tarrytown, NY) with enzymatic quantification. The serum low density lipoprotein (LDL) cholesterol was calculated from the equation: LDL cholesterol $=\mathrm{TC}-(\mathrm{HDLc})-(\mathrm{TG} / 5)$, where $\mathrm{TC}$ is total cholesterol, HDLc is HDL cholesterol, and TG are triglycerides.

Cardiopulmonary fitness and insulin sensitivity were determined in a subset of 12 subjects with paraplegia. Fitness was determined by an upper body ergometry metabolic stress test. Determination of fitness was accomplished by measurement of oxygen uptake $\left(\mathrm{V}_{2}\right)$, carbon dioxide production $\left(\dot{\mathrm{V}} \mathrm{CO}_{2}\right)$, minute ventilation (VE), heart rate (HR), and work (watts). ${ }^{22,23} \mathrm{~A}$ metabolic cart (system 2900, Sensor Medics Corp, Yorba Linda, CA) was used to measure $\dot{\mathrm{V}} \mathrm{O}_{2}, \dot{\mathrm{V}} \mathrm{CO}_{2}$, and VE. A heart rate telemeter (Polar Pacer, Computer Instruments Corp) was used to measure HR. Work was measured by use of a Fleisch Universal Ergostat upper extremity ergometer. A 12 watt incremental protocol ${ }^{24}$ using one minute stages was employed until the subject reached maximum effort, as determined by the following criteria: $\mathrm{R}$ $\left(\dot{\mathrm{V} C O}{ }_{2} / \mathrm{VO}_{2}\right)>1.10, \mathrm{HR} \geqslant 85 \%$ maximum predicted heart rate $(\mathrm{MPHR}=220$-age $)$, subjective exhaustion or other limiting symptoms.

An intravenous glucose tolerance test with tolbutamide was performed according to the modified minimal-model method of Bergman $^{25}$. After placement of 2 intracatheters, 4 basal samples were collected over $20 \mathrm{~min}$, after which glucose $(0.3 \mathrm{~g} / \mathrm{kg})$ was injected over one min. An additional injection of tolbutamide (Orinase i.v., Upjohn, Kalamazoo, MI) was given over $20 \mathrm{sec}, 20 \mathrm{~min}$ after glucose. Subjects with $\mathrm{BMI}<30 \mathrm{~kg} / \mathrm{m}^{2}$ were given $300 \mathrm{mg}$ tolbutamide; subjects with $\mathrm{BMI}>30 \mathrm{~kg} / \mathrm{m}^{2}$ were given $500 \mathrm{mg}$. Blood samples were collected at the following times after glucose injection: at $\mathrm{t}=0: 2,4,8,19,22,30,40,50,60$, $70,90,120$, and $180 \mathrm{~min}$. The insulin sensitivity index was calculated from the fast sampling intravenous glucose tolerance (FSIGT) test results using the program MINMOD which was run on the VAX-750 at the USC Physiology and Biophysics Department. This program accepts as input the temporal pattern of plasma insulin during the FSIGT, and must fit a simple (minimal) model of insulin-dependent glucose utilization to the measured glucose pattern.

Diagnostic classification from a standard $75 \mathrm{~g}$ oral glucose tolerance test, which was administered as part of an annual physical examination, was taken from the hospital record of each subject.

All calculations and statistical analyses were performed using the STATVIEW software program. Results are expressed as the mean value plus or minus standard error of the mean (SEM). ANOVA was used to determine the significance of differences in lipid levels among the groups. The unpaired Student's t-test was used to assess the significance of differences in lipid values 
between subjects with paraplegia or quadriplegia. Linear regression analyses were performed to determine the correlation between HDL cholesterol and triglycerides, cardiopulmonary fitness $\left(\dot{\mathrm{V}}_{2} \max \right)$, or insulin sensitivity $\left(\mathrm{S}_{\mathrm{i}}\right)$.

\section{Results}

The characteristics of the study and control groups are shown (Table I). The subjects with paraplegia and quadriplegia have a marked depression in mean serum HDL cholesterol when compared to controls (Table II). Except for serum triglycerides, which were noted to be lower in those with quadriplegia, there is no significant difference in any serum lipoprotein values between those with paraplegia or quadriplegia. The mean serum total cholesterol is significantly lower in the subjects with SCI compared to controls, due in part to the depressed mean serum HDL cholesterol level (Table II). The mean serum LDL cholesterol is not significantly different between those with paraplegia or quadriplegia or between either group with SCI and the control group.

Table I Characteristics of study group

\begin{tabular}{lccc}
\hline & Paraplegia & Quadriplegia & Control \\
\hline Age & $49.5 \pm 1.9$ & $46.2 \pm 2.0$ & $48.8 \pm 1.8$ \\
BMI & $26.0 \pm 0.5$ & $24.0 \pm 0.8$ & $26.8 \pm 0.7$ \\
DOI & $17.6 \pm 1.7$ & $15.0 \pm 1.7$ &
\end{tabular}

BMI $=$ body mass index $\left(\mathrm{kg} / \mathrm{m}^{2}\right) ; \mathrm{DOI}=$ duration of injury (yrs). Results are expressed as mean \pm SEM.
Since the ratio of total serum cholesterol to HDL cholesterol, as well as the ratio of serum LDL cholesterol to HDL cholesterol, has been found to be strongly correlated with the risk of $\mathrm{CHD},{ }^{26,27}$ these ratios have been determined in our subjects (Table III). In the group with paraplegia compared to the control group, a significant difference is noted between the ratio of total cholesterol to HDL cholesterol and the ratio of LDL cholesterol to HDL cholesterol. An additional significant difference is noted in the group comprising all subjects with SCI compared to the control group for the ratio of LDL cholesterol to HDL cholesterol.

An inverse correlation is noted between serum HDL cholesterol and triglyceride values in subjects with paraplegia $(p<0.0001)$ and quadriplegia $(p<0.005)$, and in controls $(p<0.005)$ (Fig 1). A direct correlation is noted between the serum HDL cholesterol values and $\dot{\mathrm{VO}}_{2}$ max, $p=0.10$. In a subgroup of 12 subjects with paraplegia, there is a significant linear correlation $(p=0.02)$ between serum HDL cholesterol and insulin sensitivity (Fig 2 ).

Table III Ratio of total cholesterol or LDL cholesterol to HDL cholesterol

\begin{tabular}{lll}
\hline Groups & TC/HDLc & LDLc/HDLc \\
\hline SCI & $5.1 \pm 0.1$ & $3.5 \pm 0.1^{*}$ \\
Paraplegia & $5.5 \pm 0.3^{*}$ & $3.5 \pm 0.2^{*}$ \\
Quadriplegia & $4.9 \pm 0.2$ & $3.4 \pm 0.2$ \\
Control & $4.6 \pm 0.2$ & $3.0 \pm 0.1$ \\
\hline
\end{tabular}

$\mathrm{TC}=$ total cholesterol, HDLc $=$ HDL cholesterol, LDLc $=$ LDL cholesterol.

ANOVA was used to determine statistically significant changes among groups.

$*_{p}<0.05$.

Table II Characteristics of study group

\begin{tabular}{lccr}
\hline Serum & Paraplegia & Quadriplegia & Control \\
lipoproteins & $37 \pm 1^{*}$ & $40 \pm 1^{*}$ & $48 \pm 2$ \\
HDL cholesterol & $191 \pm 5^{*}$ & $188 \pm 6^{*}$ & $210 \pm 4$ \\
Total cholesterol & $124 \pm 5$ & $128 \pm 6$ & $136 \pm 4$ \\
LDL cholesterol & $148 \pm 15$ & $101 \pm 8^{\bullet}$ & $134 \pm 11$ \\
Triglycerides & & &
\end{tabular}

Serum lipoproteins levels expressed as mean \pm SEM in $\mathrm{mg} / \mathrm{dL}$. ANOVA was used to determine statistically significant changes among groups.

- $p<0.0001,{ }^{*} p<0.01, \bullet p<0.05$. 

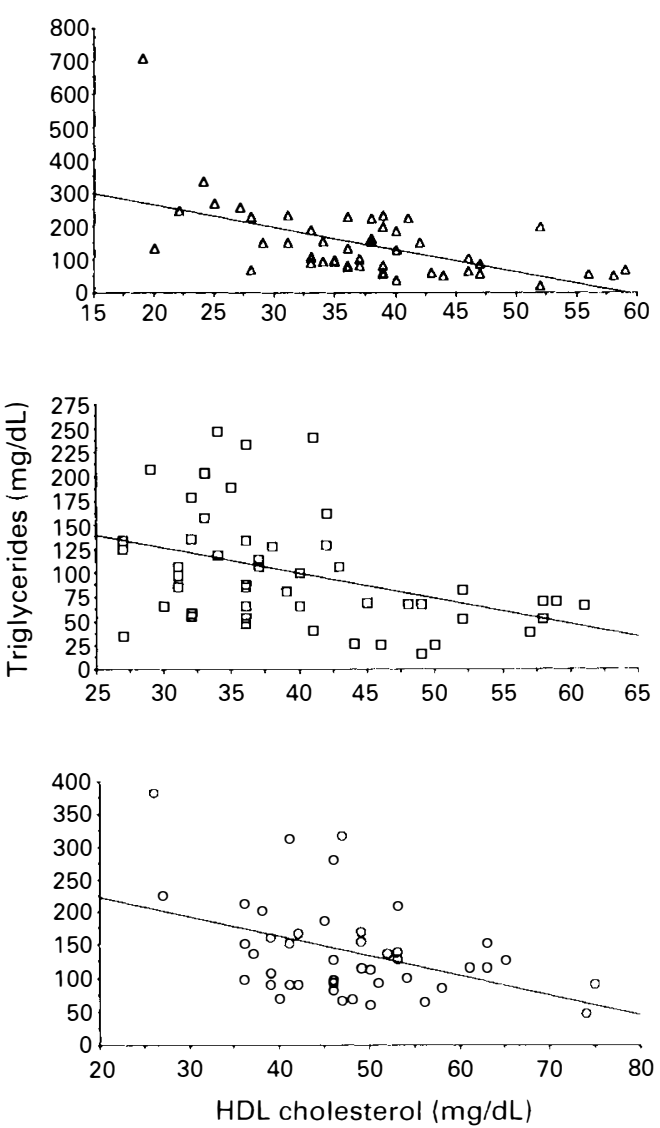

Figure 1 Correlations between triglycerides and HDL cholesterol in veterans with paraplegia (top, triangles), and quadriplegia (middle, squares), and control subjects (bottom, circles).

The serum HDL cholesterol levels were divided into 3 groups: less than 30, 30-34, and levels equal to or greater than $35 \mathrm{mg} / \mathrm{dL}$ (Table IV). There is no significant difference in the serum HDL cholesterol distribution between subjects with paraplegia and those with quadriplegia. Forty percent of subjects with paraplegia and $34 \%$ of those with quadriplegia have serum HDL cholesterol levels less than $35 \mathrm{mg} / \mathrm{dL}$.

Similarly, serum LDL cholesterol values were divided into 3 groups: less than 130 , 130 to 160 , and greater than $160 \mathrm{mg} / \mathrm{dL}$ (Table $\mathrm{V}$ ). There is no significant difference in levels of LDL cholesterol distribution between subjects with paraplegia and those with quadriplegia. Eighteen percent of indi-

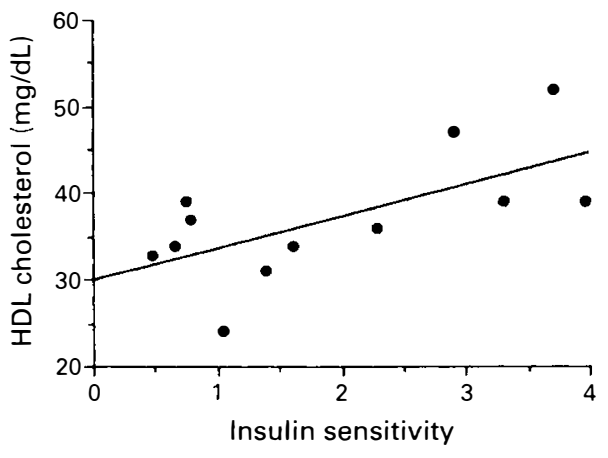

Figure 2 Correlation between HDL cholesterol and insulin sensitivity as determined by the minimal-model method. ${ }^{25}$ Insulin sensitivity is expressed in units $10^{-4} \mathrm{~min}^{-1}$ per $\mu \mathrm{u} / \mathrm{ml}$.

Table IV Serum HDL cholesterol levels $(\mathrm{mg} / \mathrm{dL})$

\begin{tabular}{lccc}
\hline Group & HDL-C & \# of subjects & Percent \\
\hline SCI & $<30$ & 13 & 13 \\
& $30-34$ & 24 & 24 \\
Paraplegia & $\geqslant 35$ & 63 & 63 \\
& $<30$ & 9 & 18 \\
& $30-34$ & 11 & 22 \\
Quadriplegia & $\geqslant 35$ & 30 & 60 \\
& $<30$ & 4 & 8 \\
& $30-34$ & 13 & 26 \\
& $\geqslant 35$ & 33 & 66 \\
\hline
\end{tabular}

Table V Serum LDL cholesterol levels $(\mathrm{mg} / \mathrm{dL})$

\begin{tabular}{lccc}
\hline Group & LDL-C & \# of subjects & Percent \\
\hline SCI & $<130$ & 56 & 56 \\
& $130-160$ & 26 & 26 \\
Paraplegia & $>160$ & 18 & 18 \\
& $<130$ & 29 & 58 \\
& $130-160$ & 14 & 28 \\
Quadriplegia & $>160$ & 7 & 14 \\
& $<130$ & 27 & 54 \\
& $130-160$ & 12 & 24 \\
& $>160$ & 11 & 22 \\
\hline
\end{tabular}

viduals with SCI have an absolute elevation of LDL cholesterol, ie greater than $160 \mathrm{mg} / \mathrm{dL} ; 7$ of these 18 subjects also have a serum HDL cholesterol less than $35 \mathrm{mg} / \mathrm{dL}$, thus having 2 independent risk factors of 
CHD. Of the 26 subjects with SCI and serum LDL cholesterol values between 130 and $160 \mathrm{mg} / \mathrm{dL}, 11$ have depressed serum HDL cholesterol levels, thus having one relative and one absolute risk factor of CHD.

The serum lipoprotein profile was divided by the carbohydrate tolerance of the subjects with SCI (Table VI). No significant difference in lipoprotein profile is demonstrated between groups with normal, impaired or diabetic oral glucose tolerance.

\section{Discussion}

Several reports have revealed lower HDL cholesterol levels in persons with SCI. ${ }^{12-14}$ The Framingham Study ${ }^{6,7}$ and other epidemiological studies ${ }^{10,11}$ have reported an inverse relationship between the HDL cholesterol level and CHD. In this report, we noted a depressed mean serum HDL cholesterol level in subjects with paraplegia and quadriplegia compared to mean values in able bodied controls. Almost $40 \%$ of the subjects with SCI had serum HDL cholesterol levels below $35 \mathrm{mg} / \mathrm{dL}$, an independent risk factor of CHD. In the subjects with SCI and in the controls, strong inverse correlations were demonstrated between serum triglycerides and HDL cholesterol. This inverse relationship may reflect the effects of plasma insulin, elevated as a consequence of reduced peripheral insulin sensitivity, on lipid metabolism. Hyperinsulinemia may cause increased hepatic triglyceride production, ${ }^{19}$ which, in turn, tends to lower serum HDL cholesterol, perhaps by enhancing clearance mechanisms. ${ }^{16}$

Brenes et al $^{13}$ reported that in relatively

Table VI Serum lipoprotein profile in SCI when divided by carbohydrate tolerance

\begin{tabular}{lrrrrrr}
\hline Lipoprotein & \multicolumn{1}{c}{ NL } & \multicolumn{2}{c}{ IGT } & \multicolumn{2}{c}{ DM } \\
\hline HDL cholesterol & $39 \pm$ & 1 & $38 \pm$ & 2 & $39 \pm$ & 2 \\
total cholesterol & $189 \pm$ & 6 & $199 \pm$ & 8 & $186 \pm$ & 7 \\
LDL cholesterol & $125 \pm$ & 5 & $134 \pm$ & 8 & $124 \pm$ & 7 \\
triglycerides & $124 \pm 17$ & $130 \pm 14$ & $123 \pm$ & 15 \\
\hline
\end{tabular}

Results are expressed as mean \pm SEM young and inactive men with SCI the mean serum HDL cholesterol level was depressed, whereas in highly trained wheelchair athletes the mean value for serum HDL cholesterol was closer to normal levels. No significant difference was noted between mean serum HDL cholesterol levels in inactive subjects with paraplegia or quadriplegia. ${ }^{13}$ Dearwater et $a l^{14}$ noted that in untrained men with SCI, the mean serum HDL cholesterol level was depressed compared to the mean value in wheelchair athletes. In a small number of subjects Hooker and Wells ${ }^{28}$ addressed the effects of low intensity and moderate intensity wheelchair ergometry exercise on lipids. Only in the moderate intensity exercise group was a significant increase in serum mean HDL cholesterol level demonstrated. It should be noted, however, that the mean serum HDL cholesterol value before exercise training in the low intensity group was higher than the mean value after exercise training in the moderate exercise group.

There are additional lipoprotein measurements or mathematical expressions that have been associated with risk of CHD. In a recent study, ${ }^{26}$ the ratio of serum total cholesterol to HDL cholesterol was a particularly strong discriminator of risk of myocardial infarction. An increase of one unit was associated with a mean increase of $53 \%$ in the risk of myocardial infarction. ${ }^{26}$ Subjects with paraplegia in our report had about a one unit increment in this ratio compared with the control group. The inverse relationship between serum HDL cholesterol and risk of myocardial infarction appeared stronger for men with lower levels of total cholesterol, ${ }^{26}$ such as those with SCI in this report. This ratio was a stronger predictor of risk than was total cholesterol, total HDL cholesterol, subfractions of HDL cholesterol, or levels of apolipoproteins. ${ }^{26}$ The ratio of LDL cholesterol to HDL cholesterol may be a better indicator of risk of $\mathrm{CHD}$ in individuals with SCI since a depressed HDL cholesterol lowers total cholesterol but does not affect LDL cholesterol. Hence, the additional significant difference between the control group and the subjects with SCI was present when this latter ratio was used rather than the ratio of 
total cholesterol to HDL cholesterol. Other measurements, such as alipoprotein B-100 (the main apoprotein in the LDL particle) and alipoprotein A-I (one of the apoproteins in the HDL particle), as well as other lipid and/or apoprotein ratios (B-100 to HDL cholesterol or B-100 to A-I), may also be significant predictors of risk of $\mathrm{CHD}$ in the person with SCI. A properly controlled, long term prospective study of $\mathrm{CHD}$ morbidity and mortality in relationship to lipoprotein and apoprotein values in per- sons with SCI will provide us with this information.

\section{Acknowledgements}

This research was supported in part by the Merit Review Research Program of the Veteran Affairs Medical Center and the Eastern Paralyzed Veterans Association. We acknowledge the Spinal Cord Injury Service of the Bronx Veterans Affairs Medical Center for their assistance. We thank Ms Arline Vargas for her expert secretarial assistance.

\section{References}

1 Duckworth WC, Solomon SS, Jallepalli P, Heckemeyer C, Finnern J, Powers A (1980) Glucose intolerance due to insulin resistance in patients with spinal cord injuries. Diabetes 29: 906-910.

2 Whiteneck G (1992) Learning from empirical investigations. In: R Menter and G Whiteneck, editors. Demos Publications. Perspectives on Aging with Spinal Cord Injury: 23-37.

3 US National Spinal Cord Injury Statistical Center (1986) EJ Kennedy and SL Stover, editors. Spinal Cord Injury, the Facts and Figures. University of Alabama, Birmingham, Alabama.

4 Geisler WO, Jousse AT, Wynne-Jones M, Breithaupt D (1983) Survival in traumatic spinal cord injury. Paraplegia 21: 364-373.

5 Samsa P, Patrick C, Feussner JR (1987) A national study of mortality among spinal cord injured veterans. IIR \#87-036.

6 Kannel WB, Castelli WP, Gordon T (1979) Cholesterol in the prediction of atherosclerotic disease: new perspectives based on the Framingham study. Ann Intern Med 90: 85-91.

7 Castelli WP (1984) Epidemiology of coronary heart disease: The Framingham study. Am J Med 76(2A): 4-12.

8 Castelli WP, Leaf A (1985) Identification and assessment of cardiac risk - an overview. Cardiol Clin 3(2): 171-178.

9 Castelli WP, Doyle JT, Gordon T, Hames CG, Hjortland MC, Hulley SB et al (1977) HDL-Cholesterol and other lipids in coronary heart disease: the cooperative lipoprotein phenotyping study. Circulation 55: 767-772.

10 Goldbourt U, Medalie JH (1979) High density lipoprotein cholesterol and incidence of coronary heart disease: The Israeli ischemic heart disease study. Am J Epidemiol 109: 296-308.

11 Leon AS, Blackburn H (1977) The relationship of physical activity to coronary heart disease and life expectancy. Ann NY Acad Sci 301: 561-578.

12 LaPorte RE, Brenes G, Dearwater S, Murthy MA, Cauley JA, Dietrick R et al (1983) HDL cholesterol across a spectrum of physical activity from quadriplegia to marathon running. Lancet 1: 1212-1213.

13 Brenes G, Dearwater S, Shapera R, LaPorte RE, Collins E (1986) High density lipoprotein cholesterol concentrations in physically active and sedentary spinal cord injured patients. Arch Phys Med Rehabil 67: 445-450.

14 Dearwater SR, LaPorte RE, Robertson RJ, Brenes G, Adams LL, Becker D (1986) Activity in the spinal cord-injured patient: an epidemiologic analysis of metabolic parameters. Med Sci Sports Exerc 18: 541-544.

15 Reaven GM (1988) Banting lecture 1988: Role of insulin resistance in human disease. Diabetes 1595-1607.

16 Golay A, Zech L, Shi MZ, Chiou YAM, Reaven GM, Chen YDI (1987) High density lipoprotein (HDL) metabolism in noninsulin-dependent diabetes mellitus: measurement of fHDL turnover using tritiated HDL. $J$ Clin Endocrinol Metab 65: 512-518.

17 Abrams JJ, Ginsberg H, Grundy SM (1982) Metabolism of cholesterol and plasma triglycerides in nonketotic diabetes mellitus. Diabetes 31: 903-910.

18 Orchard TJ, Becker DJ, Bates M, Luller LH, Drash AL (1983) Plasma insulin and lipoprotein concentrations: an atherogenic association? Am J Epidemiol 118: 326-333.

19 Reaven GM, Greenfield MS (1981) Diabetic hypertriglyceridemia: evidence for three clinical syndromes. Diabetes 30(2): 66-75.

20 LaPorte RE, Adams LL, Savage D, Brenes G, Dearwater S, Cook T (1984) The spectrum of physical activity and cardiovascular disease: an epidemiologic perspective. Am J Epidemiol 120: 507-517.

21 Wood PD, Haskell WL, Blair SN (1983) Increased exercise level plasma lipoprotein concentrations: a one-year, randomized controlled study in sedentary middle-aged men. Metabolism 32: 31-39.

22 Astrand P, Rodahl K (1977) Evaluation of physical work capacity on the basis of tests. In: P Astrand, K Rodahl, editors. Textbook of Work Physiology, 2nd ed. McGraw-Hill, New York: 333-365. 
23 Wasserman K, Hansen J, Sue D, Whipp B (1987) Physiology of exercise. In: K Wasserman, J Hansen, D Sue, B Whipp, editors. Principles of Exercise Testing and Interpretation. Lea \& Febiger, Philadelphia: 3-26.

24 Spungen AM, Bauman WA (1991) A protocol for performing arm-crank ergometry thallium cardiac stress testing in paraplegics. Clin Res 39A(2): 406.

25 Bergman RN, Praguer R, Volund A, Olefsky JM (1987) Equivalence of the insulin sensitivity index in man derived by the minimal model method and the euglycemic glucose clamp. J Clin invest 79: 790-800.

26 Stampfer MJ, Sacks FM, Salvini S, Willett WC, Hennekens CH (1991) A prospective study of cholesterol, apolipoproteins, and the risk of myocardial infarction. $N$ Eng J Med 325: 373-381.

27 Manninen V, Huttunen JK, Heinonen OP, Tenkanen L, Frick MH (1989) Relation between baseline lipid and lipoprotein values and the incidence of coronary heart disease in the Helsinki heart study. Am J Cardiol 63: $42 \mathrm{H}-47 \mathrm{H}$.

28 Hooker SP, Wells CL (1989) Effects of low- and moderate-intensity training in spinal cord-injured persons. Med Sci Sports Exerc 21: 18-22. 